\title{
Optimization of the parameters of the sewing thread cutting process
}

\author{
Yuri Novikov ${ }^{1}$ and Stas Krasner $^{1}$ \\ 1 - Vitebsk State Technological University, Department of Information Systems and Automation of Production, 210035, 72 Moscow \\ Uprospect, Vitebsk , Belarus \\ Corresponding author contact: nov_u_vik@mail.ru
}

\begin{abstract}
Sewing thread cutting processes are widely used in semi-automatic machines of the garment industry, and is a highly topical issue. There is no scientifically based methodology for designing thread trimming mechanisms for semi-automatic sewing machines.

Cutting threads by the method of scissors does not provide complete cutting of all components of the thread in case of insufficient pressing of the knife planes to each other. To ensure complete trimming, a design cutting scheme has been developed and calculation formulas have been obtained for determining the force exerted by the thread on the movable knife, taking into account the mechanical characteristics of the cut sewing thread.
\end{abstract}

Keywords: cutting of sewing threads, movable knife, blade, properties of threads, offset of knives, cutting processes, thread trimming.

\section{Formulation of the problem.}

Thread cutting in automated sewing machines is a necessary part of the process. Trimming mechanisms are included in the cycle of the machine, and their failure leads to disruption of the process. Kapustin, II, (1950 and 1966) was the first who argued that the cutting force of a material depends on the physicomechanical properties, thickness, and also on the magnitude of blunting of the cutting edge and the angle of sharpening of the knife blade. The process of cutting a thread with a blade is not sufficiently studied, and the design of thread trimming mechanisms was not given due attention (Valshchikov, 1973, Komissarov, 1978, Zak, 1977, Garbaruk, 1977, Polukhin, 1972, Arkhipov 1983, Polukhin, 1970). As indicated in the analysis of the existing designs of needle and shuttle thread trimming mechanisms on sewing machines, wedge sharpening blades working on the principle of scissors are used as tools.

The design of the knife blades, material and heat treatment being commonly known today, it was decided to accept these parameters as constant, and to take variables related to the parameters of the thread trimming process (knife pressing force, knife closing speed, sewing thread tension).

To determine the factors the trimming process is conditioned upon, an experimental complex was made and mounted, including an experimental setup, an amplifier, and a recorder (Kuzmin, 1982, Artobolevsky, 1965, Kapustin, 1980). In our installation, the cutting tool is made of HVG steel, and its geometric parameters are assumed constant, taking into account the recommendations (Kapustin, 1980). In the process of designing the installation, the recommendations set forth in the literature were taken into account (Yascheritsyn, 1985, Tikhomirov, 1974, Vinogradov, 1970). The ten-factor experiment is rather complicated, therefore, at the initial stage, the ranking of factors was carried out in order to simplify the experiment.

Description of the developed experimental setup (Figure 1). On the plate 1 mounted on the legs 2, a fixed 3 and a movable 4 knives are fixed with a screw 5. On each knife is a load cell 6, fixing the deformation of the knife in the process of trimming the thread. The strain gauge is connected with an amplifier, and that, in turn, is connected with a recorder fixing the deformation of the knives on the tape. 
The pressing force of the knives is regulated by pressing the clamping screw 5 , the pressing is reflected in the initial deformation and recorded by the recorder. A preliminary experiment and calibration was carried out, reflecting the actual values of the deformation.

The installation provides for the adjustment of the thread tension force. For this, a bracket 7 is mounted on the plate 1 , in which a hole is made. A thread is threaded into the hole, which is inserted from above into the holder 8 and fixed by the stopper 9 . A mass 11 is suspended from the bottom of the thread, which is fixed by the stopper 12. The magnitude of the thread tension changes by changing the mass of the suspended load.

The installation provides for the adjustment of the closing speed of the knives.

The spring 19 is used for adjustment. One end of the spring is clamped in the holder 20 and fixed by the stopper 21, and the other is engaged with the rigid insert 18, which, in turn, is attached to the movable knife 4 . The clamping speed is changed by replacing the rigid insert 18 . The length of the hard inserts was selected during the preliminary experiment, since it affects the speed of closure of the knives.

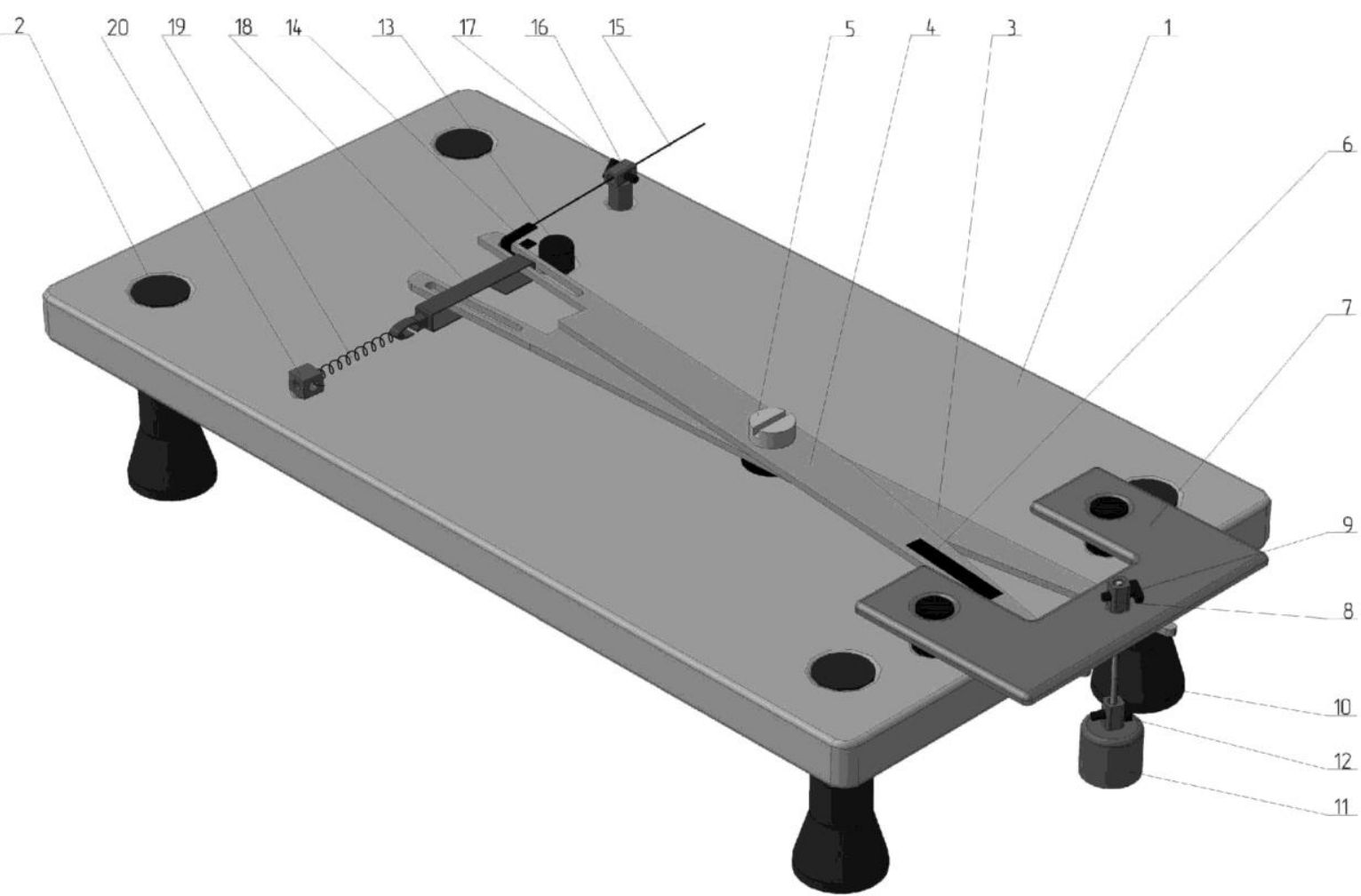

Fig. 1. The experimental setup.

To bring the installation to its basic position, it is necessary to pull on the cable 15 , which is connected with the hook 14. The movable knife 4 is withdrawn to the extreme position, adjustable by the stopper 13. The cable 15 is fixed in the holder by the stopper 17.

To conduct the experiment, the following steps were considered necessary to follow: use screw 5 to establish the necessary pressure of the knives, the value of pressure is checked on the recorder; thread the test thread into the hole of the bracket 7 and holder 8 , fix it with the stopper 9 , hang the load of the necessary mass 11 to the bottom of the thread; we connect the spring 19 with a rigid insert, pull the cable 15 until the stop of the movable knife 4 in the stop 13 and fix the stopper 17 in the starting position.

The installation is ready for the experiment. We take out the stopper 17, the knives are closed, under the action of the spring 19, the thread 10 is trimmed or not trimmed. 


\section{$2 \quad$ Measuring the force of pressing of knives.}

Strain gauges are located on the knives of the experimental setup, which are connected by a bridge circuit to increase the load sensitivity with small bends of the sensitive beam. A unified semiconductor strain gauge amplifier (accuracy class 2.0) is used to amplify the signal from the bridge circuit of the strain gauges to the desired value. The output signals from it are fed to a fast-recording recorder (accuracy class 1.5 ), where they are converted into graphic information on paper.

The cutting force measurement was done through a measuring complex that uses two channels for determining the cutting force. The principle of operation of the device is based on the amplification of the direct current of the strain gauge signals, and it has been developed for one-way communication with a three-channel recorder (one channel is free), which records the readings on a paper tape.

As a result of the interaction of the knives with each other and with the thread being cut, elastic deformations of the recording elements occur. Since the sensing elements work in the zone of elastic deformations, then after the load is removed, the beams will return to their original position.

\section{Calibration Sequence.}

On each knife there was a strain gauge to record the deformation of the knife. In the zone where the knife interacts with the thread, the cargo of known mass was suspended $(5,10,15 \mathrm{~g})$. The deformation is meticulously recorded by the recorder.

Figure 2 features graphs of the dependent deviation of the recorder pen on the magnitude of the load.

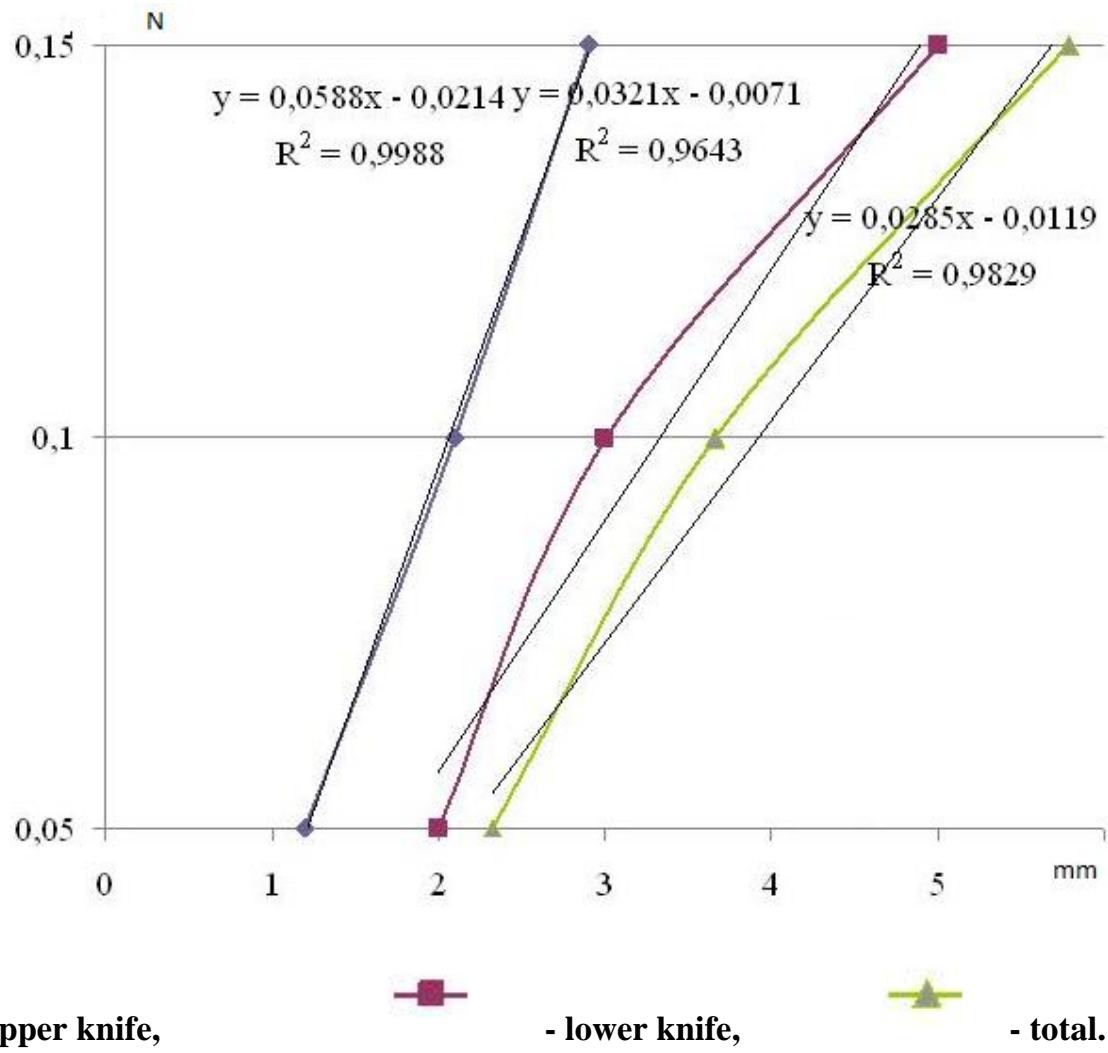

Fig. 2. Graphs of the dependent deviation of the recorder pen on the magnitude of the load.

In the installation, a spring was used to impart speed to the knives. Under the action of the spring, the knives were set in motion. Rigid inserts of various lengths are provided in the experimental setup to 
change the speed of knife closure. Determining the closing speed of knives is possible by analyzing the setup and the diagram obtained by cutting the scissors with thread.

The course of the knives in the experimental setup remains constant, since the amount of knife cultivation is limited by a stopper and is equal to $10,4 \mathrm{~mm}$.

Table 1. Dependence of the deviation of the recorder pen on the magnitude of the load.

\begin{tabular}{|l|l|l|l|}
\hline $\begin{array}{c}\text { The magnitude of the } \\
\text { loading blades of scis- } \\
\text { sors, } \mathrm{N}\end{array}$ & $\begin{array}{c}\text { Deviation of the pen } \\
\text { of the recorder for the } \\
\text { upper knife, [mm] }\end{array}$ & $\begin{array}{c}\text { Deviation of the pen } \\
\text { of the recorder for the } \\
\text { lower knife, [mm] }\end{array}$ & $\begin{array}{c}\text { Deviation of the pen } \\
\text { of the recorder with the } \\
\text { simultaneous loading of } \\
\text { two knives, [mm] }\end{array}$ \\
\hline 0,05 & 1,2 & 2 & 2,33 \\
\hline 0,1 & 2,1 & 3 & 3,66 \\
\hline 0,15 & 2,9 & 5 & 5,78 \\
\hline
\end{tabular}

Figure 3 shows the process of trimming the thread on the tape of the recorder, which made it possible to determine the closing speed of the knives with a known set of parameters of the speed of drawing the tape in the recorder (B - knives closing time, L - knife stroke).

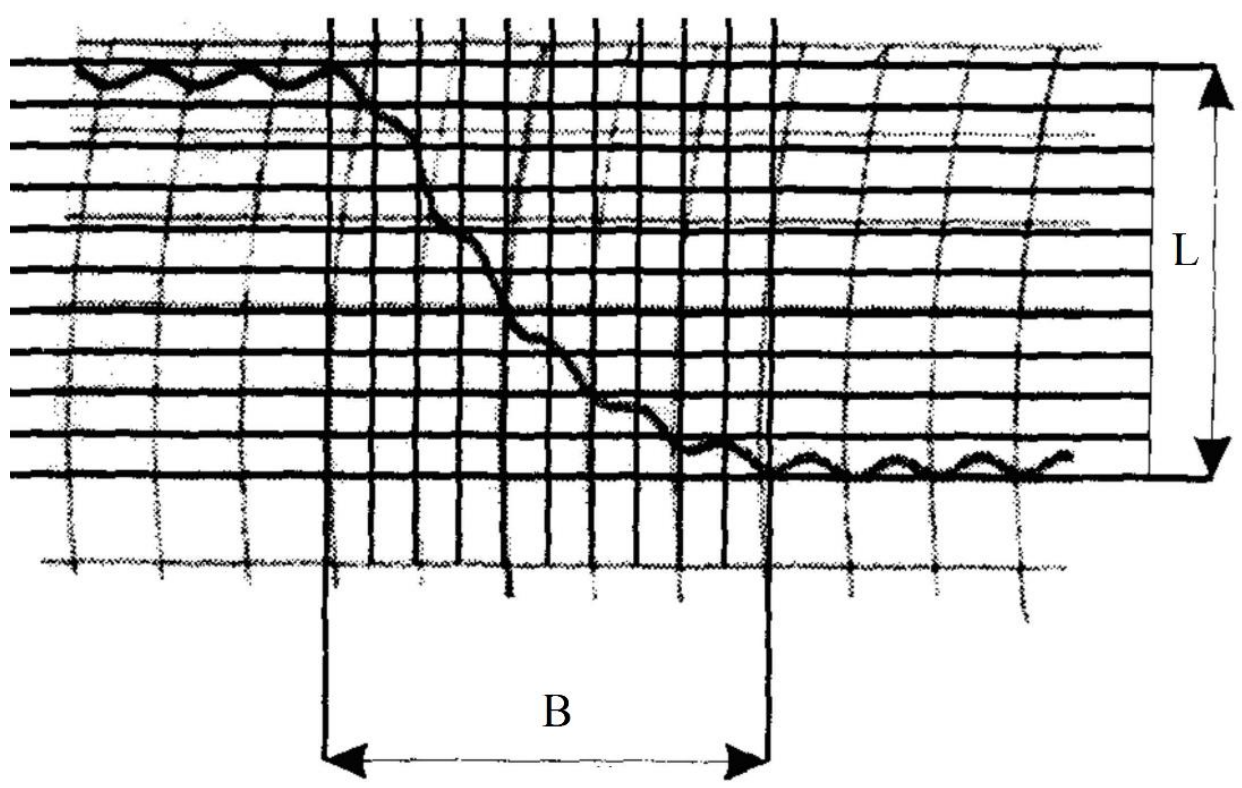

Fig. 3. The diagram of the closing of the knives at speed $V=0,101 \mathrm{~m} / \mathrm{s}$.

The speed of closing the knives is $\mathrm{V}_{1}=0,1 \mathrm{~m} / \mathrm{s}$.

The installation provides for the possibility of changing the tension of the threads. To do this, a weight of the 3rd accuracy class of fixed mass was suspended from string 10. Figure 4 shows a diagram of the regulation of the thread tension force in an experimental setup.

As the study, necessarily, should confirm the adequacy of the analytical description of the cutting process of the sewing thread, an experiment was performed on the setup described above. The experimental conditions are consistent with the actual tension conditions of the sewing thread during the 
operation of the embroidery semiautomatic device $(0.2 \mathrm{~N})$. The knives were closed (manually) with a reduced speed, $\mathrm{m} / \mathrm{s}$.

\section{$4 \quad$ The experiment was carried out for embroidery thread Sulky 40.}

2 .

The parameters of the dependence of the thread deformation on the impact force are taken from table

In accordance with the algorithm described earlier, the values of the force of pressing the knives are $\mathrm{NX}=0.95 \mathrm{~N}$.

Variable parameter of the experiment adopted the force of pressing the knives NX .

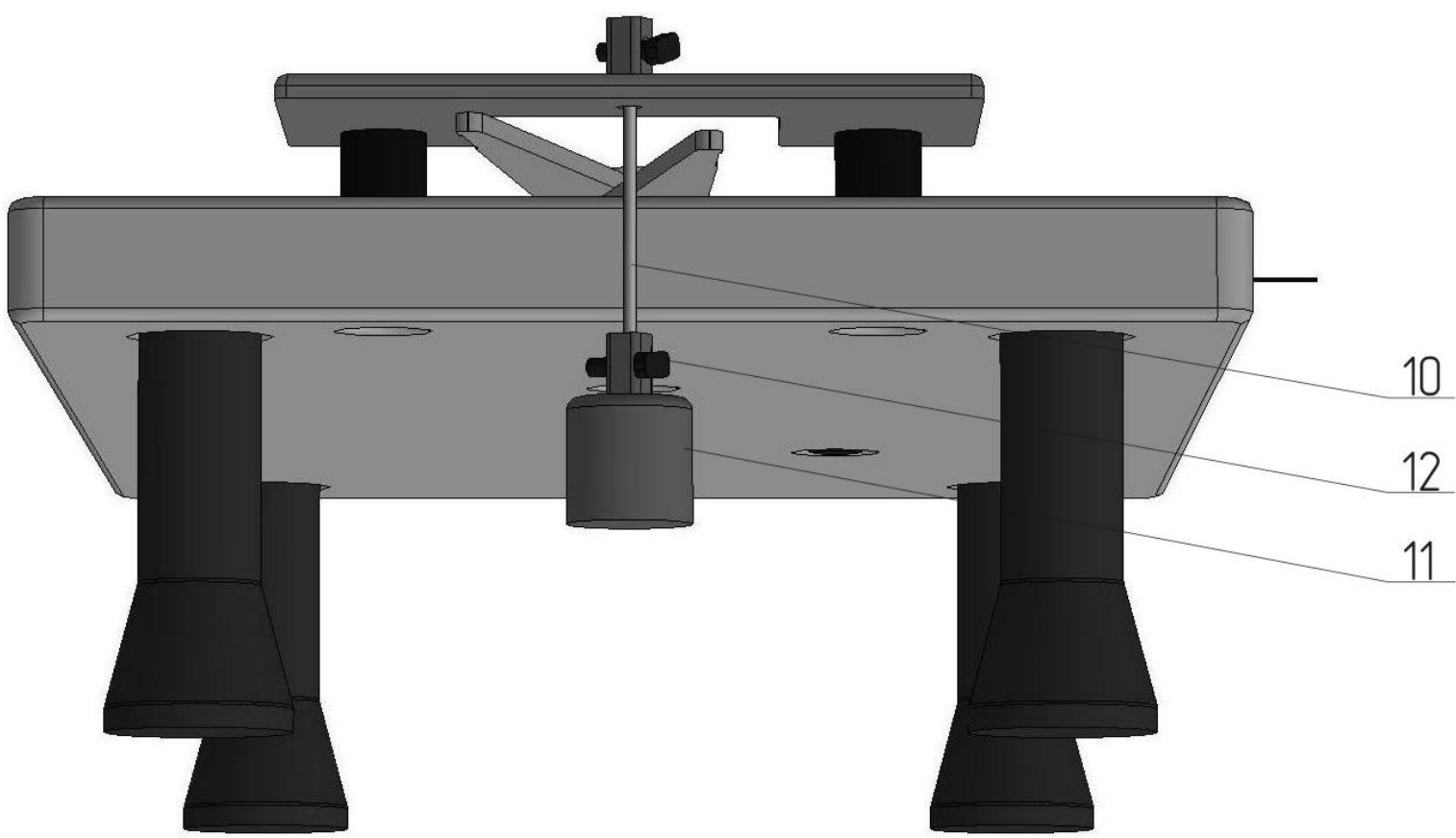

Fig. 4. The schematic of regulation of the tension force of the thread in the experimental setup.

We use the interval $(0.93 \ldots 0.97 \mathrm{~N})$ in increments of $0.02 \mathrm{~N}$.

The studied value is the probability of trimming:

$$
P=\frac{m}{N},
$$

where

$m$ - is the number of experiments in which complete thread trimming occurs;

$N$ - total number of experiments.

To obtain the reliability of the experiment, equal to $97 \%, 100$ repetitions of each experiment were carried out.

Guaranteed trimming is ensured when the knife pressing force $\mathrm{NX}=0.97 \mathrm{~N}$, the analytical description of the cutting process of the sewing thread showed the value of the knife pressing force $\mathrm{NX}=0.95$ $\mathrm{N}$. 
Table 2. The results of the experiment to verify the adequacy of the analytical description of the process of cutting the sewing thread.

\begin{tabular}{|l|l|l|}
\hline Knife pressing force $N_{X},[\mathrm{~N}]$ & $P$ - probability of cropping & Number of experiments, $\mathrm{m}$ \\
\hline 0,93 & 0,96 & 100 \\
\hline 0,95 & 0,99 & 100 \\
\hline 0,97 & 1 & 100 \\
\hline
\end{tabular}

It is established that the deviation of the results obtained during the experiment and according to the analytical description is:

$$
\Delta=\left|\frac{N_{\text {хтеор. }}-N_{\text {хэкс. }}}{N_{\text {хтеор. }}}\right| \cdot 100 \%=2,1 \%,
$$

which is less than the permissible value of $5 \%$ and officially confirms the adequacy of the analytical description of the process.

\section{Preliminary experiment.}

It was carried out in laboratory conditions of Vitebsk State Technological University (Vitebsk, Belarus).

When forming the planning matrix for constructing the mathematical model, it was determined that the force of pressing the knives against each other, the closing speed of the knives, and the tension force of the sewing thread influence the studied indicator of the quality of trimming sewing threads.

The choice of experiment strategy was determined at the initial stage and was comparatively unformalized.

The experiment planning matrix is a table in which the values of the factor levels obtained in different series of experiments are indicated. The number of experiments is determined by the objectives of the study and experimental design methods.

To obtain the reliability of the experiment, equal to $97 \%, 100$ repetitions of each experiment were carried out.

\section{The planning of an active multifactor experiment.}

Limitations were imposed on the change in the input parameters during the experiment, which were caused by a preliminary experiment and technical considerations, as well as an earlier analysis of the physics of the process of cutting the sewing thread.

The value of the main levels of factors is selected on the basis of a preliminary experiment so that the optimization parameter ( $\mathrm{P}$ - the probability of cropping) has the best values.

Having determined the values of the main levels of factors, we proceed to the choice of the factor variable interval. The values of the upper and lower levels of the factor determine the boundaries of the studied local area. The maximum value of the shoulder is chosen so as not to go beyond the boundaries of a possible area of change of the factors. In our case, the interval of variation of factors was chosen on the basis of a preliminary experiment, experience, and intuition.

A wide range of variation was chosen for all factors. As the object of the experimental study, we use the threads selected in the second chapter.

In order to find the limits for measurement of the surveyed parameters, we will conduct a preliminary experiment Tikhomirov, 1974, Vinogradov, 1970). During a preliminary experiment, we investigated the thread cutting of Sulky 40. 
Table 3. Sulky 40 Factor Levels and Intervals.

\begin{tabular}{|c|c|c|c|c|c|c|}
\hline \multirow{2}{*}{ Name of factor } & \multirow{2}{*}{ Symbol } & \multirow{2}{*}{$\begin{array}{l}\text { Designa- } \\
\text { tion of } \\
\text { thread }\end{array}$} & \multicolumn{3}{|c|}{ Variation level } & \multirow{2}{*}{$\begin{array}{l}\quad \text { Varia- } \\
\text { tion inter- } \\
\text { val }\end{array}$} \\
\hline & & & -1 & 0 & +1 & \\
\hline $\begin{array}{l}\text { The force of pressing } \\
\text { the knives to each other, } \\
\mathrm{Q} 1,[\mathrm{~N}]\end{array}$ & $X_{1}$ & \multirow{3}{*}{$14,5 \times 2$} & $0^{0,4}$ & $0^{0,6}$ & $0^{0,8}$ & 0,40 \\
\hline $\begin{array}{c}\text { Closing speed of } \\
\text { knives, V1, }[\mathrm{m} / \mathrm{s}]\end{array}$ & $X_{2}$ & & $2^{0,0}$ & $25^{0,0}$ & $3^{0,0}$ & 0,01 \\
\hline $\begin{array}{l}\text { The tension force of the } \\
\text { sewing thread, } \mathrm{P},[\mathrm{N}]\end{array}$ & $X_{3}$ & & 0 & $5^{0,3}$ & 0,7 & 0,7 \\
\hline
\end{tabular}

Established, on the grounds $f$ a preliminary experiment, was the fact that the function of the dependence of the cutoff probability on the input parameters can be quite accurately described by a polynomial. Determined, accordingly, were the relevant levels and variable intervals of the factors as described in table 3.
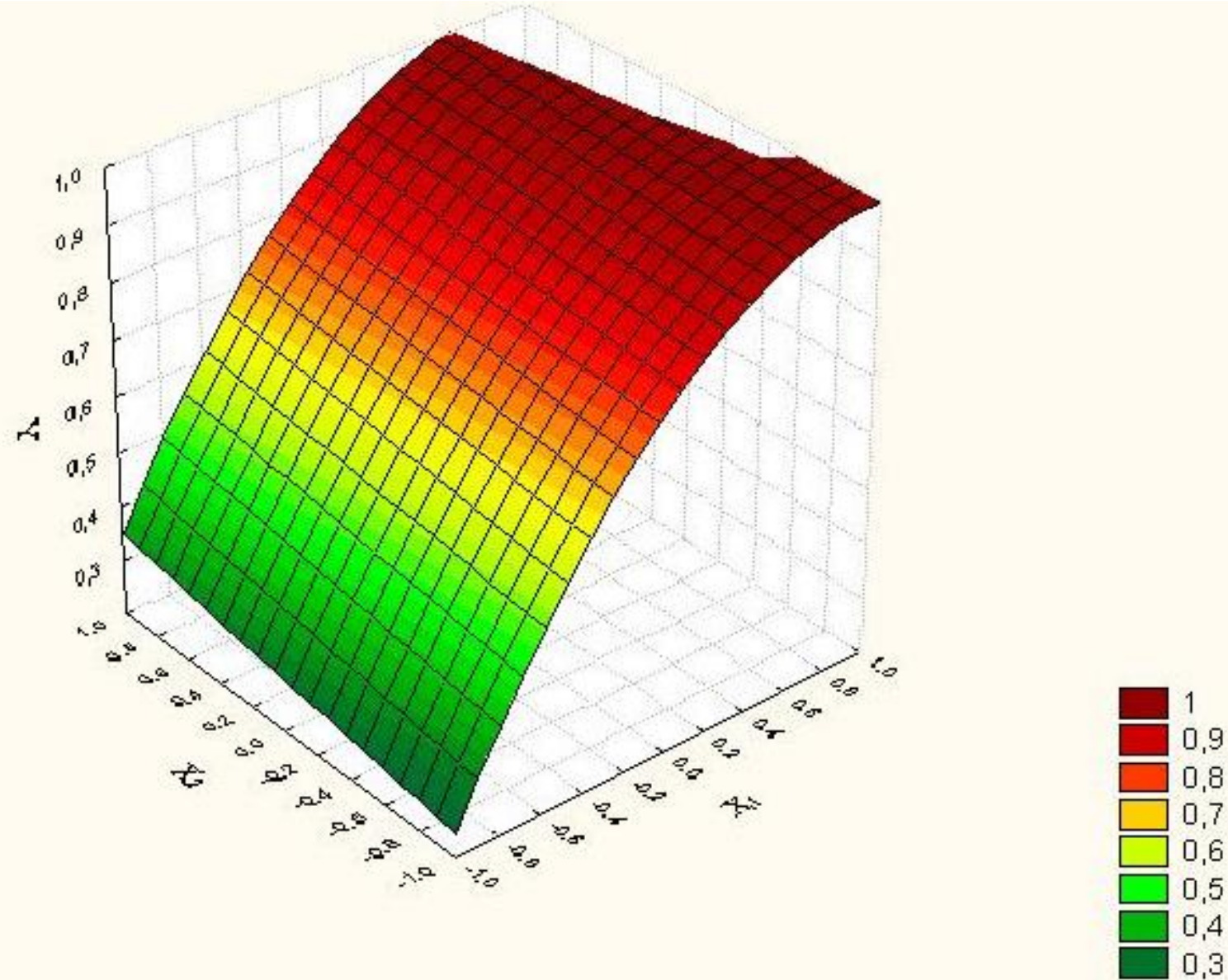

Fig. 5. Graphical interpretation of the dependence of the probability of cutting on the closing force or pressing of the knives and the tension force $\mathrm{P}$ of the thread in the trimmer mechanism. 


\section{The main experiment.}

To search for optimal values of the most significant parameters of the technological process of trimming sewing threads that provide the best quality indicators, we used mathematical methods for planning and analyzing the experiment.

For the purposes of the present paper, a complete factorial experiment with three factors was carried out. In most sewing machines and sewing machines, two threads are simultaneously trimmed - needle and shuttle, so we will change the object of study and cut two threads.

\section{Study into the process of joint trimming of two Sulky 40threads}

The experiment planning matrix and the calculated values as to the number of cuts per 100 measurements for the Sulky 40 thread are presented in Table 4.

The data obtained during the experiment were processed using a software package "Statistica for Windows" on a computer. The coefficients of the polynomial model are determined with a confidence level of $95.0 \%$.

The significance of the regression coefficients was determined using Student's criterion:

$$
t_{R}=\frac{A_{i}}{S(A)},
$$

where

$A_{i}$-is the output parameter;

$S(A)$ - the standard deviation of the regression coefficient.

The calculated value of the criterion was compared with the table. If, then the regression coefficient was considered significant. Otherwise, the regression coefficient was equal to zero and the corresponding factor was excluded from the equation.

The coefficients for the polynomial model of the form are determined according to the formula:

$$
Y=a_{1}+a_{2} \cdot x_{1}+a_{3} \cdot x_{2}+a_{4} \cdot x_{3}+a_{5} \cdot x_{1} \cdot x_{2}+a_{6} \cdot x_{1} \cdot x_{3}+a_{9} \cdot x_{1}^{2} .
$$

The significance of the regression coefficients was determined using Student's criterion.

The coefficients for the polynomial model of the form are determined as follows:

$$
Y=a_{1}+a_{2} x_{1}+a_{4} \cdot x_{3}-a_{7} \cdot x_{1} \cdot x_{3}-a_{11} \cdot x_{3}^{2} .
$$

Table 5 shows the values of the parameters of the polynomial model for the thread defined in the program "Statistica for Windows".

The adequacy of the obtained models was checked according to the Fisher criterion. A model is considered adequate if the calculated value of the Fisher criterion does not exceed the tabular one. For all the obtained models, therefore, the hypothesis of the adequacy of the models is not rejected.

The dependence of the probability of the process of joint trimming of two Sulky 40 threads by Gunold (14.5 tex'2) on the process parameters was computed using the equation: 


$$
Y=0,925-0,253 x_{1}+0,213 x 3-0,188 x_{1} x_{3}-0,272 x_{3}^{2} .
$$

To build graphical models (Figure 6), dependencies of the probability of cropping, we use the software package "Statistica for Windows" on a computer.

Table 4. Boxing matrix of experiment planning and obtained values of the number of cuts per 100 measurements for Sulky 40 thread.

\begin{tabular}{|c|c|c|c|c|c|}
\hline$?$ & $\mathrm{x} 1$ & $\mathrm{x} 2$ & $\mathrm{x} 3$ & $\mathrm{Y}$ & $\begin{array}{l}\text { Number of clip- } \\
\text { pings from } 100 \text { ex- } \\
\text { periments }\end{array}$ \\
\hline 1 & -1 & -1 & 1 & 0,57 & 57 \\
\hline 2 & -1 & -1 & -1 & 0,07 & 7 \\
\hline 3 & -1 & 0 & 0 & 0,83 & 83 \\
\hline 4 & -1 & 1 & 1 & 1 & 100 \\
\hline 5 & -1 & 1 & -1 & 0 & 0 \\
\hline 6 & 0 & -1 & 0 & 0,87 & 87 \\
\hline 7 & 0 & 0 & 1 & 0,77 & 77 \\
\hline 8 & 0 & 0 & -1 & 0,13 & 13 \\
\hline 9 & 0 & 1 & 0 & 1 & 100 \\
\hline 10 & 1 & -1 & 1 & 1 & 100 \\
\hline 11 & 1 & -1 & -1 & 1 & 100 \\
\hline 12 & 1 & 0 & 0 & 1 & 100 \\
\hline 13 & 1 & 1 & 1 & 1 & 100 \\
\hline 14 & 1 & 1 & -1 & 1 & 100 \\
\hline
\end{tabular}

We pose the problem of determining the ranges of the pressing force of the knives against each other, the speed of the knives closing, and the tension of the sewing thread within the given variable intervals of the factors at which the probability of complete thread trimming would be equal to 1 .

Table 5. Parameter values of the polynomial model for Sulky 40.

\begin{tabular}{|l|l|l|}
\hline Significance coefficients & Parameter & P-value \\
\hline a1 & 0,925 & 0,000 \\
\hline a2 & 0,253 & 0,002 \\
\hline a4 & 0,213 & 0,005 \\
\hline
\end{tabular}




\begin{tabular}{|l|l|l|}
\hline a7 & $-0,188$ & 0,019 \\
\hline a11 & $-0,272$ & 0,035 \\
\hline
\end{tabular}

To solve this problem, it is necessary to analyze the graphical interpretations of the dependence of the probability of cutting on the closing force of knives and the tension force of the thread in the thread trimming mechanism and polynomial models.

After analyzing the graphical interpretations and models, the necessary range of operating parameters of the trimming mechanism for the Sulky 40 thread was established: pressing force of knives over 0.72 $\mathrm{N}\left(\mathrm{x}_{1}>0.6\right)$; thread tension force over $0.7 \mathrm{~N}\left(\mathrm{x}_{3}>1\right)$.

The results of the study were applied in the design of the trimming mechanism on a multi-head embroidery semiautomatic device.

Since Sulky 40 type embroidery threads are used on the semi-automatic embroidery machine, the operating parameters are oriented to the values obtained for this thread. The pressing force of the knives to each other is required by the experiment $0.72 \mathrm{~N}$, and for the reduced speed of movement of the knives, the pressing force was $0.95 \mathrm{~N}$, which is more than $0.72 \mathrm{~N}$, therefore, taking the values of the pressing force for low speeds, we provide guaranteed trimming at high speeds developed by the drive of the automatic thread trimming mechanism (the closing speed of the knives is $0.2 \mathrm{~m} / \mathrm{s}$ ). Having set the safety factor for the pressing force of the knives, and taking into account the trimming of two threads and the deterioration of the cutting conditions (blunting of the knives), we were able to ensure guaranteed thread trimming on the modernized semiautomatic device. The tension force of the sewing thread is adopted over $0.7 \mathrm{~N}$. For the shuttle thread, this force is regulated by the shuttle spring, and for the needle thread by the needle thread tension unit. A study on the reliability of the trimming mechanism for multi-head embroidery semiautomatic machine showed a guaranteed trimming of sewing thread.

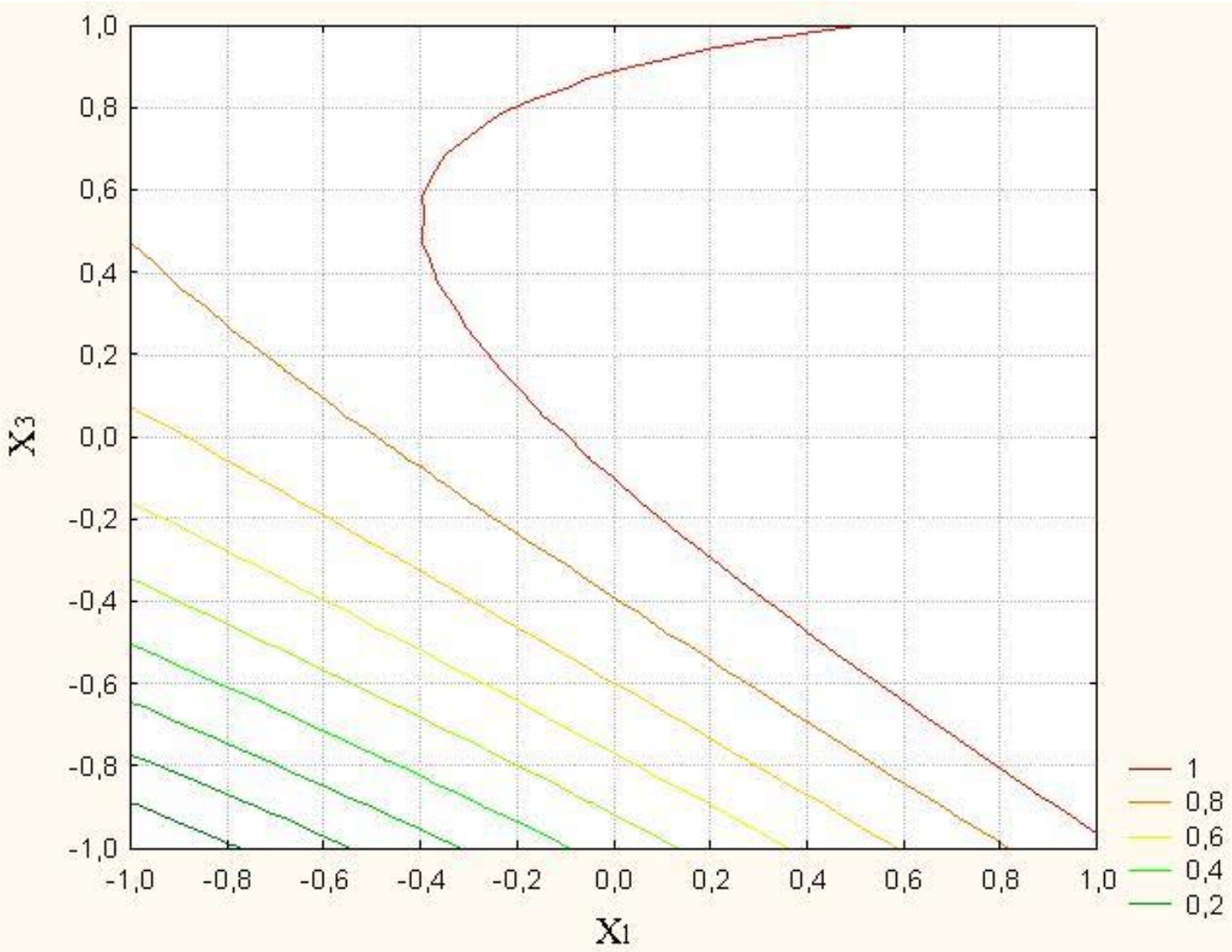


Fig. 6. Graphic dependence of the probability of trimming the Sulky 40thread from the force of pressing the knives and the tension force of the thread.

For a number of threads and yarns used in sewing a wide range of garments, the physical and mechanical properties of threads were studied using the developed experimental setup.

\section{Conclusion}

1. An experimental study of the cutting process was carried out on a machine simulating the cutting process in real conditions in semi-automatic machines with MPU by the experimental design method, and the ranges of varied factors were established: knife pressing force $\mathrm{N}_{\mathrm{x}}[0.4 \ldots 0.8] \mathrm{N}$, knife closing speed $\mathrm{V}_{1}[0,02 \ldots 0,03] \mathrm{m} / \mathrm{s}$, the tension force $\mathrm{P}$ of the thread $[0 \ldots 0,7] \mathrm{N}$; as an optimization criterion, the probability of complete trimming of the sewing thread is accepted. It was found that the deviation of the results obtained during the experiment and according to the analytical description is $2.1 \%$. The experiment confirms the adequacy of the analytical description of the process.

2. The method of mathematical planning of the experiment yields non-linear regression equations for the dependence of the probability of complete thread trimming on these factors, adequate by the Fisher criterion and significant by the Student criterion. The obtained models make it possible to assess the significance of factors affecting full trimming, and it was also found that the most significant factors are the pressing force $\mathrm{N}_{\mathrm{x}}$ of the knives and the tension force $\mathrm{P}$ of the thread.

3. The problem of determining the ranges of the values of the pressing force $\mathrm{N}_{\mathrm{x}}$ of the knives, the closing speed of the knives $\mathrm{V}_{1}$ and the tension force $\mathrm{P}$ of the thread, at which the probability of complete trimming will be equal to 1 . The required range of operating parameters of the trim mechanism for the thread Sulky 40: the pressing force of the knives over $0.72 \mathrm{~N}$; thread tension force over $0.7 \mathrm{~N}$.

4. Multiple studies of the designed and implemented automatic trimming mechanism have confirmed the achievement of guaranteed trimming of sewing threads while observing the recommended operating parameters. The results of the study were applied in the design of the trimming mechanism on a multihead embroidery semiautomatic device.

\section{References}

Kapustin, I.I. (1950). Cutting and cutting tools: a textbook for universities. I.I. Kapustin. - Moscow: Gizlegprom, 377 p.

Kapustin, I.I. (1966). Automatic machines and automatic lines in the sewing and shoe production: textbook for universities. II. Kapustin, I.I. Galynker. - Minsk: Light industry, 422 p.

Valshchikov, N.M. (1973). Calculation and design of sewing machines. N.M. Valschikov, B.A. Zaitsev, Yu.N. Fellers. - Leningrad: Mechanical Engineering, 344 p.

Komissarov, A.I. (1978). Design and calculation of machines for shoe and sewing industries. A.I. Komissarov [et al.], under the editorship of A.I. Komissarova. - Moscow: Engineering, 431 p.

Zak, I.S. (1977). Adaptations and aggregate units for sewing machines. I.S. Zach -Moscow: Light industry.

Garbaruk, V.P. (1977). Calculation and design of the main mechanisms of shuttle sewing machines. V.N. Garbaruk. - Leningrad: Mechanical Engineering, 232 p.

Polukhin, V.P. (1972). Design of the mechanisms of sewing and basting machines. V.P. Polukhin. Moscow: Engineering, 280 p. 
Arkhipov, N.N. (1983). Fundamentals of the design and calculation of typical machines and apparatuses of light industry: a textbook for universities. NN. Arkhipov [et al.]. - Moscow: Mashgiz, $599 \mathrm{p}$.

Polukhin, V.P. (1970). Methods and means of automatic thread trimming on sewing machines. V.P. Polukhin, V.N. Sokolov, V.A. Uymanov. - Moscow: TSNIITEIlegpishchemash, 76 p.

Kuzmin A.V. (1982). Course design of machine parts: a reference guide. Part 1. A.V. Kuzmin [et al.]. - Minsk: Higher School, 208 p.

Artobolevsky, I.I. (1965). Theory of mechanisms. I.I. Artobolevsky. - Moscow: Science. S. 764-769.

Kapustin, I.I. (1980). Cutting and cutting tools. I.I. Kapustin. - Moscow: Light Industry, 191 p.

Yascheritsyn, P.I. (1985). Planning an experiment in mechanical engineering. PI. Yascheritsyn, E.I. Maharinsky. - Minsk: Higher school, 286 p.

Tikhomirov, V.B. (1974). Planning and analysis of the experiment (when conducting research in the light and textile industries). V.B Tikhomirov. - Moscow: Light Industry, 262 p.

Vinogradov, Yu.S. (1970). Mathematical statistics and its application in the textile industry. Yu.S. Vinogradov. - Moscow: Light Industry, 312 p. 